\title{
REVISTAMATËRIA
}

\section{Mechanical characteristics of groundnut shell particle reinforced polylactide nano fibre}

\author{
Samson Adeosun ${ }^{1}$, Omotayo Taiwo ${ }^{1}$, Emmanuel Akpan ${ }^{2}$, \\ Oluwashina Gbenebor ${ }^{1}$, Sadiq Gbagba ${ }^{1}$, Samuel Olaleye ${ }^{3}$
}

\begin{abstract}
${ }^{1}$ Department of Metallurgical and Materials Engineering, University of Lagos, Lagos, Nigeria samsonoluropo@yahoo.com

${ }^{2}$ Department of Materials and Production Engineering, Ambrose Ali University, Ekpoma, Nigeria 3Department of Mechanical Engineering, University of Lagos, Lagos, Nigeria.

taiwooluwaseyi2003@yahoo.com, emma_eia@yahoo.com, gbeneborphilips@yahoo.co.uk, sadiqgbagba@gmail.com, solaleye@unilag.edu.ng
\end{abstract}

\begin{abstract}
The PLA-groundnut shell solution is electrospun to produce nanocomposite fibre. The spinneret containing the composite solution was placed $24.7 \mathrm{~cm}$ away from the aluminium collector, tilted at an angle of $30^{\circ}$, and the solution flow rate kept at $1 \mathrm{~mL} / \mathrm{min}$. Groundnut Shell particle (GSP) weight fraction used was varied from 3 - 8 wt. \%. Particle reinforced nanofibres were formed on the collector from the composite solution at $26 \mathrm{kV}$. These nanofibres were subjected to tensile test and the result indicates that at $6 \mathrm{wt}$. \% untreated GSP reinforced fibre possessed the best tensile stiffness of $24.62 \mathrm{MPa}$. This corresponds to $2.201 \%$ increase in Modulus of Elasticity over the unreinforced PLA (1.07 MPa). The 7 wt. \% treated GSP fibre showed the least stiffness $(0.33 \mathrm{MPa})$, which is $69 \%$ reduction over that of unreinforced fibre. PLA fibre reinforced with 5 wt. $\%$ untreated GSP displayed best blend of properties over the unreinforced with increase of $286 \%$ (4.43 x $10^{-4}$ HB), 1,502 \% (1.07 MPa), $286 \%$ (0.22 MPa), $6.8 \%(0.05 \mathrm{~J})$ and 1,081 \% ( $0.15 \mathrm{MPa})$ in hardness, stiffness, UTS, energy at break and stress at break respectively. However, ductility decreased by $~ 33.3 \%$ when compared to the unreinforced (18.27). The $5 \mathrm{wt}$. \% untreated GSP PLA reinforced fibre showed the highest UTS $(0.855 \mathrm{MPa})$. The micrographs showed beads on reinforced fibres, while the virgin PLA showed no beads.
\end{abstract}

Keywords: Groundnut shell particle, Polylactic acid, nano fibre composite, electrospinning, morphology

\section{INTRODUCTION}

Natural fibres have been extensively used as reinforcements in polymer matrices instead of non-degradable synthetic fibres such as carbon, glass or aramid. The use is because of their low-density, good mechanical properties, availability and biodegradability. Development of nanofibres using agro wastes or lignocellulosic materials as reinforcing fillers with biodegradable polymers through electrospinning is currently the focus of attention. Groundnut shell is one of such natural agro waste filler used and it contains cellulose, hemicellulose and lignin. Natural fibre/particle sources are not only strong and lightweight but are relatively very cheap. The use of groundnut shell particles (GSP) to reinforce Vinyl ester resin (GSPC) has resulted in improvement in tensile strength and Modulus of Elasticity [1]. The reviewed of study on the mechanical and morphological properties of PLA-based (reinforced with wood flour/talc) composites prepared by melt compounding and injection moulding showed tensile modulus of the composite to increased from 62.5$169.5 \%$ contrary to earlier studies where no improvement was recorded [2].

Study [3] on wood flour reinforced polypropylene revealed improvement in the composite flexural modulus and tensile modulus with increasing filler loading. However, declines occur in the composite flexural strength, tensile strength, elongation at break and impact strength with increasing filler loading. The study [4] on tensile properties of treated and untreated groundnut shell filled natural rubber composites reported that the tensile strength of the composite decreases with increase in fibre loading of the composites for both treated and untreated fillers (with highest value $<10 \mathrm{MPa}$ ). However, the impact energy and 
Hardness increased with filler loading.

The above reviews considered the use of biodegradable filler to reinforced synthetic polymer matrix without eliminating the attendant problem of environmental pollution occasioned by the degradation products of fossil based polymer matrix. Therefore, this study examines the mechanical and morphological responses of GSP reinforced poly lactic acid (PLA) fibre. Both matrix and filler are biodegradable and there is no fear of environmental pollution during degradation.

\section{MATERIALS AND METHODS}

The matrix PLA pellets were procured from Suzhou, China. The groundnut shell was obtained from ground nut fruit purchased from a local market in Lagos State Nigeria. The groundnut fruits were first washed with water and detergent to remove contaminants, and boiled with Alum, salt, and water to allow easy removal of shells. For the untreated shells, these were sundried for three days $\left(33^{\circ} \mathrm{C}\right)$, grounded and sieved to $150 \mu \mathrm{m}$ particle size. For the treated ground nut shell, the shells were cut into small pieces after been sundried, ground to pass a screen of $10 \mathrm{~mm}$ in a mechanical crusher. The ground shells were first de-waxed with benzene - ethanol treatment in a Soxhlet extractor, washed to neutrality and oven dried at a temperature of 45 ${ }^{\circ} \mathrm{C}$. Resulting GSPs were subjected to steam explosion at $175{ }^{\circ} \mathrm{C}$ and $1 \mathrm{bar}$ pressure in an autoclave for an explosive reaction on the fibres. Enzymatic hydrolysis was carried out on the resulting GSP using crude cellulase suspended in $50 \mathrm{~mL}$ of $50 \mathrm{mM}$ Na acetate buffer $(\mathrm{pH} 4.8)$ at $50^{\circ} \mathrm{C}$ for two hours. This was followed by alkaline hydrolysis, bleaching and acid hydrolysis. All treated GSPs were then washed in water, centrifuged in ethanol, dried in still air and ground to $150 \mu \mathrm{m}$.

Dichloromethane solvent used to dissolve the GSP and PLA was purchased from a chemical shop at Ojota, Lagos. The fibre spinning was done at a voltage of $26 \mathrm{KV}$ while the spinneret inclined at $30{ }^{\circ} \mathrm{C}$ was placed at $24.7 \mathrm{~cm}$ from the aluminium foil collector. The solution rate of flow was $1 \mathrm{~mL} / \mathrm{min}$. The GSP in the PLA matrix varied from 3-8 wt.\% in the solvent and each solution was made to $12 \% \mathrm{w} / \mathrm{v}$.

The tensile test of particle reinforced fibres produced was done using an Instron computerised double column universal tensile testing machine model 3369 located at the Energy Centre, Obafemi Awolowo University, Ile-Ife, Nigeria. It has a load capacity of $50 \mathrm{KN}$ and operates at a loading rate/strain rate of 5 $\mathrm{mm} / \mathrm{min}$. Readings were in triplicate and the average taken.

The reinforced fibre morphology was studied using an ASPEX Personal SEM (PSEM) 3020 located at Kwara State University, Malete, Nigeria. It is a tungsten filament scanning electron microscope optimized for automated particle analysis.

The water absorption test was carried out in two stages: one at ambient temperature and the other at 70 ${ }^{\circ} \mathrm{C}$. For water absorption at ambient temperature, samples of dimension $3 \mathrm{~cm} \times 3 \mathrm{~cm}$ were cut from the collectors of various nanocomposites fibre. The samples were weighed separately on a digital weighing scale. After weighing, the samples were dipped into separate $50 \mathrm{~mL}$ volume beaker filled with water. Each test sample was left in the beaker for $24 \mathrm{~h}$, then removed and weighed. The amount of water absorbed and water absorption rate were calculated using equations 1 and 2 respectively.

$$
\text { Amount of water absorbed }=\text { final weight of sample }- \text { initial weight of sample }
$$

$$
\text { Water absorption rate }=\text { Amount of water absorbed } \div \text { Initial weght of sample } \times 100
$$

The water absorption at $70^{\circ} \mathrm{C}$ involved samples of dimension $3 \mathrm{~cm} \times 3 \mathrm{~cm}$ cut from the fibres. The samples were weighed separately on a digital weighing scale using Unic Bloc Digital weighing balance (UW $1020 \mathrm{H}$ ) with tolerance of $0.001 \mathrm{~g}$. After weighing, the samples were immersed in a container of water and heated to $100{ }^{\circ} \mathrm{C}$ before the kettle was switched off. These samples were left for $30 \mathrm{~min}$ until the temperature dropped to $70{ }^{\circ} \mathrm{C}$, while the final weight of each sample was recorded. The measurements were taken simultaneously with boiling at $30 \mathrm{~min}$ intervals up till $120 \mathrm{~min}$, when the final readings were recorded. Finally, the amount of water absorbed and water absorption rate were calculated using equations 1 and 2, respectively. 


\section{RESULTS AND DISCUSSION}

\subsection{Mechanical Responses}

Figure 1 shows the ultimate tensile strength (UTS) of GSP reinforced PLA nanofibre. The UTS for the untreated GSP-PLA fibre increases with increase in filler weight fraction to a peak value of $0.87 \mathrm{MPa}$ at 5 wt. $\%$ filler but decline with further additions to a minimum of $0.1 \mathrm{MPa}$ at $8 \mathrm{wt} . \%$. The UTS for treated GSPPLA fibre is highest $(0.7 \mathrm{MPa})$ at $3 \mathrm{wt}$. \% and decreased to $0.1 \mathrm{MPa}$ at $8 \mathrm{wt}$. \%. The treated reinforced fibres' UTS is only better than untreated GSP-PLA fibre at 3 and 4 wt. \%. The initial high UTS of the treated GSP-PLA fibre can be attributed to the surface treatment, which promoted wettability and better fibre/matrix adhesion. Thus, this allows for efficient stress transfer between the matrix and the fibres [5] unlike untreated filler filled composites. The decline after saturation is attributed to agglomeration and sediment effects associated with higher filler content [6] or poor wetting between the fillers and matrix resulting in formation of micro-cracks [7]. The untreated GSP-PLA fibre showed superior UTS at $5 \mathrm{wt}$. \%, which is attributed to the filler concentration and distribution $[8,9]$.

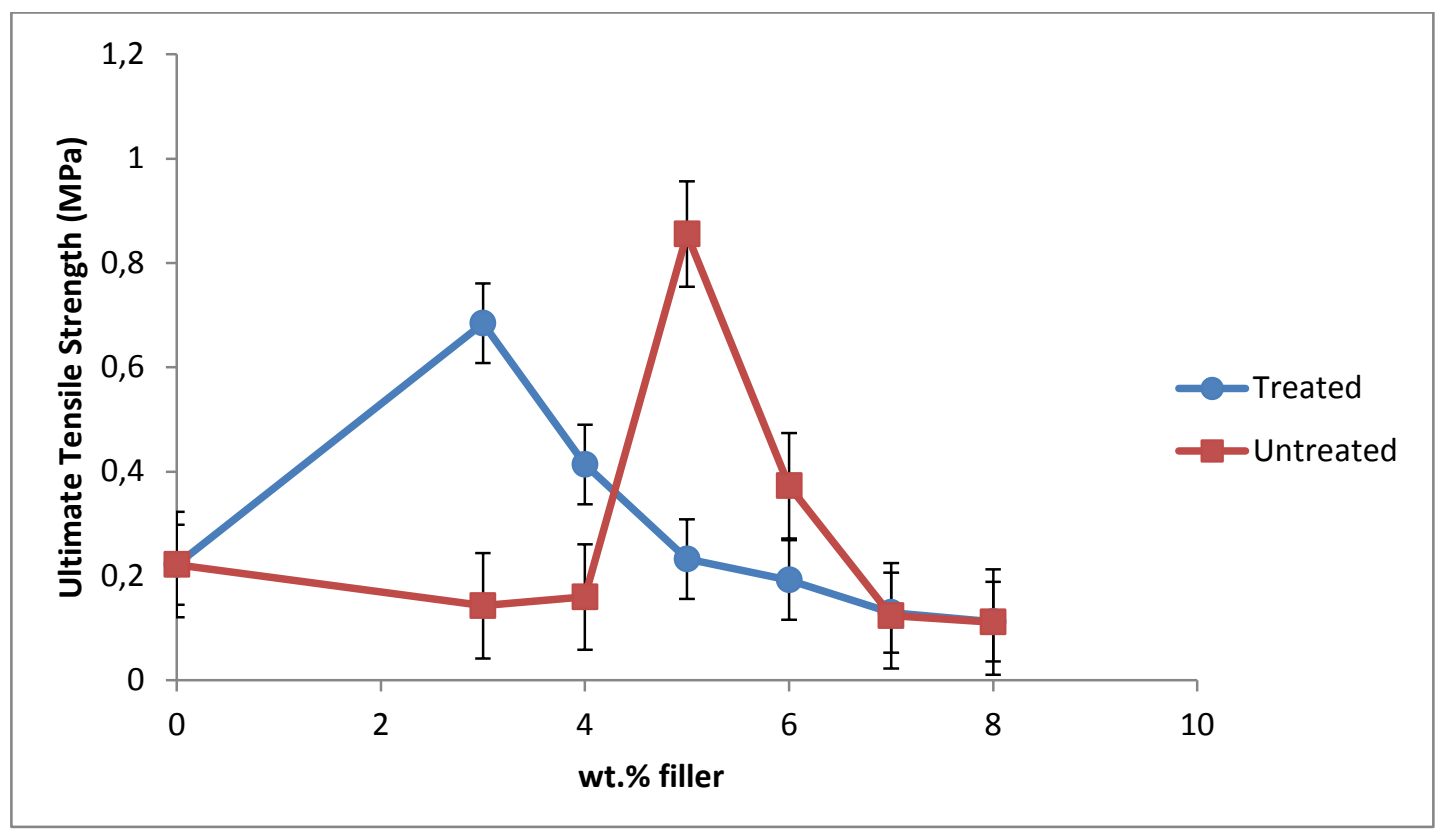

Figure 1: Ultimate Tensile Strengths of GSP-PLA nanofibre.

In Figure 2 the ductility of treated and untreated GSP reinforced PLA nanofibre is shown. The ductility of the composites reduces when compared to that of the virgin PLA as a result of increased obstruction to the motions of crazes brought about by the presence of filler particles [10,11]. Though inferior to the unreinforced PLA fibre, the ductility of untreated GSP-PLA nanofibre starts to increase from 3-7 wt. \% before it decreases at 8 wt. \%. The treated GSP-PLA fibre increases from $3-5$ wt. \% before falling to $9 \%$ at 8 wt. \%. The study observed that the treated GSP reinforced PLA nanofibres showed a higher ductility compared to the untreated GSP reinforced PLA nanofibres. It is expected that the treatment of the filler led to improved interfacial adhesion at the fibre/matrix interface, which restricts easy glide of the filler particles over the matrix giving rise to higher ductility. 


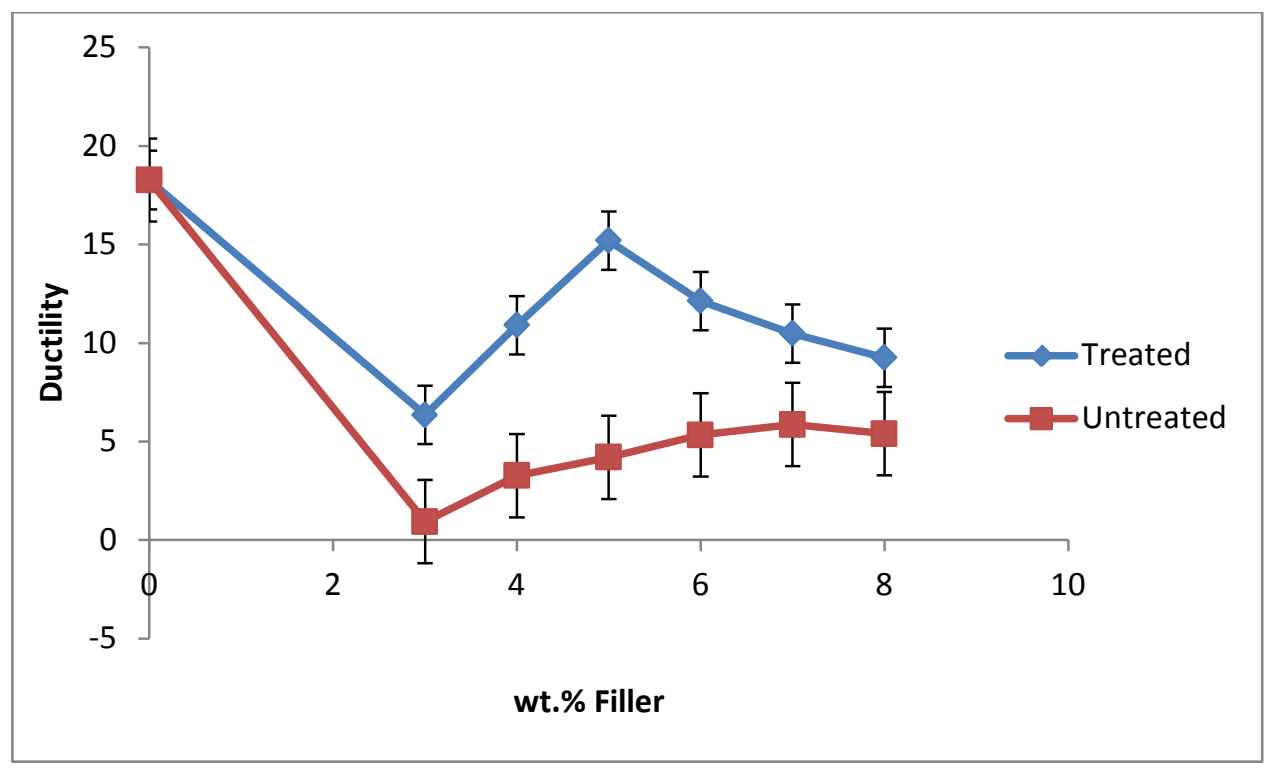

Figure 2: Ductility of GSP-PLA nanofibre.

Figure 3 shows the stiffness of treated and untreated GSP-PLA nanofibre. The untreated GSP reinforced PLA composite decreases at $3 \mathrm{wt}$. \% before increasing to peak at $6 \mathrm{wt}$ \% (25 MPa). The treated GSP reinforced PLA composite decreases from $3 \mathrm{wt}$ \% (18 MPa) before an increase at 8 wt. \%. Composites with treated fillers only show improvement at 3, 4 and 8 wt. \% when compared to composites with untreated fillers. The composites show increase in stiffness over that of unreinforced PLA fibre. The increase in stiffness of composites to that of unreinforced PLA (1 MPa) can be attributed to the restrain imposed by the incorporation of fillers to the motion of crazes in the matrix in the proximity of the particles, which consequently contributes to the enhancement in Modulus of Elasticity [11]. Elastic Modulus of polymers is basically influenced by crystallinity and cross-linking, the higher the crystallinity, the higher the Elastic Modulus. In the case of $6 \mathrm{wt}$. \% for untreated fibers it is believed that even distribution of fillers in the fibre led to increase in crystllinity and consequently increased Elastic Modulus. This can be seen in figure 9d where the fibres possess less amount of beads, indicating lack of agglomeration of filler particles.

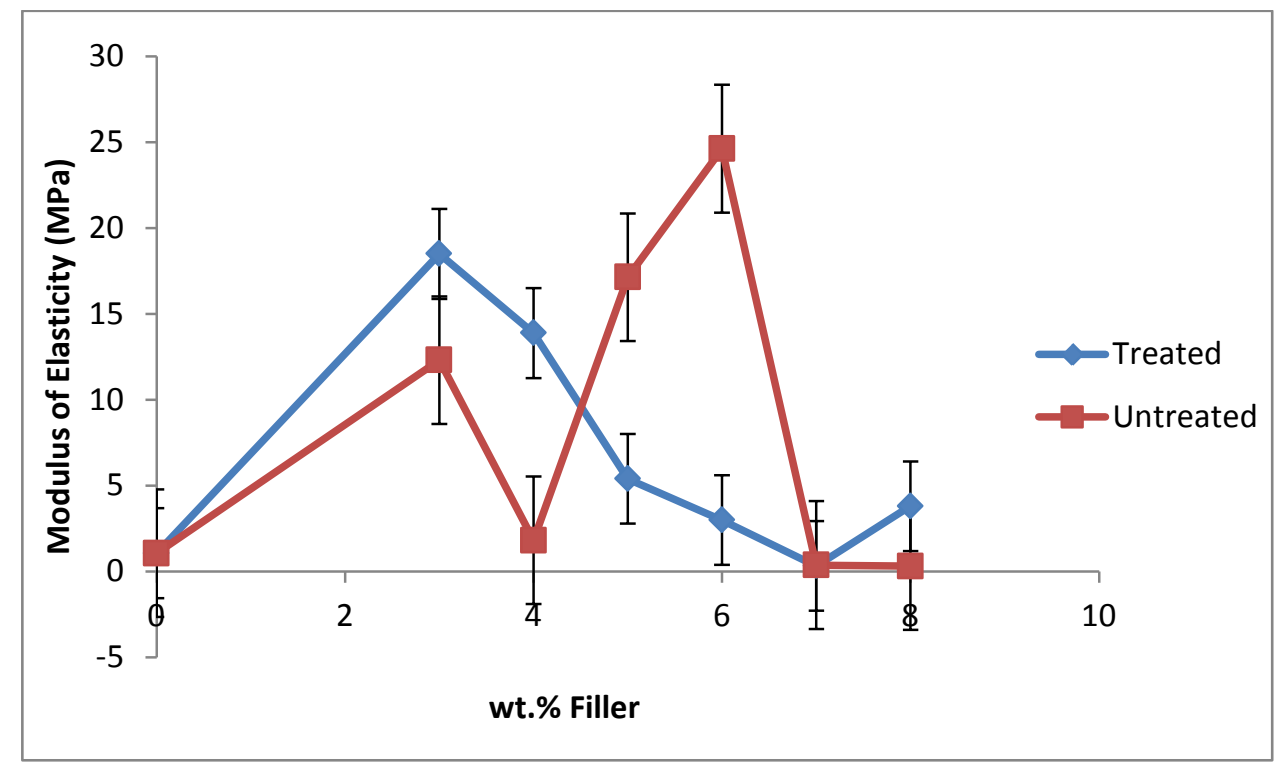

Figure 3: Modulus of Elasticity of GSP-PLA nanofibre.

Figure 4 shows the stress at break of treated and untreated GSP-PLA nanofibre. The untreated GSP reinforced composites showed superior stress at break $(0.21 \mathrm{MPa})$ at 6 wt. \% while the treated GSP 
reinforced PLA composites displayed maximum break stress is $\sim 0.025 \mathrm{MPa}$ at 4 wt. \%. Both reinforcements type decline after attaining these peaks. The treated GSP-PLA nanofibres' fracture stress is inferior to the untreated GSP-PLA fibres. The untreated particles here served as crack arresters [12] in the PLA fibre matrix and thus promoting delayed propagation of brittle fracture and early failure at lower load applications [13].

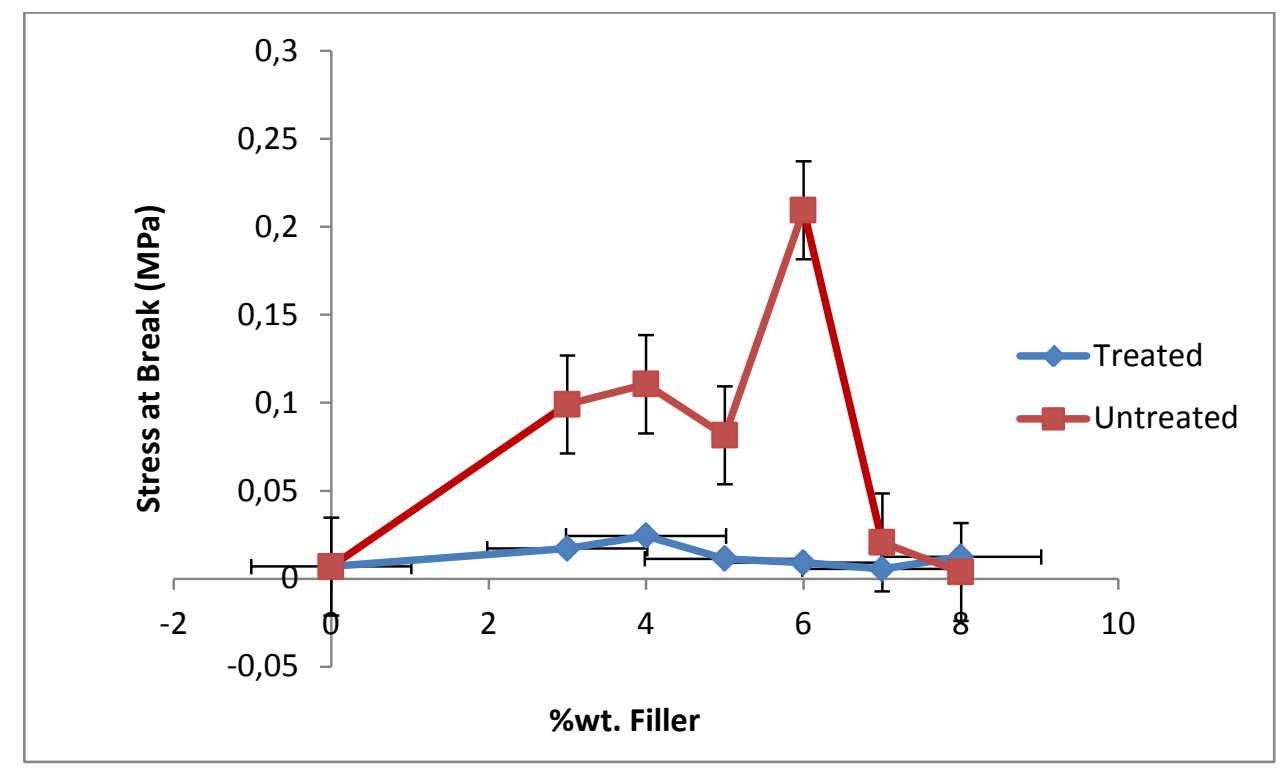

Figure 4: Stress at break of GSP-PLA nanofibre.

In Figure 5, the energy at break of treated and untreated GSP-PLA nanofibre is shown. The treated GSP reinforced PLA nanofibre shows consistently better energy at break than untreated GSP reinforced PLA nanofibre except at $5 \mathrm{wt}$. \% ( 0.057 J). This is due to higher ductility exhibited by the treated GSP-PLA fibres [14].

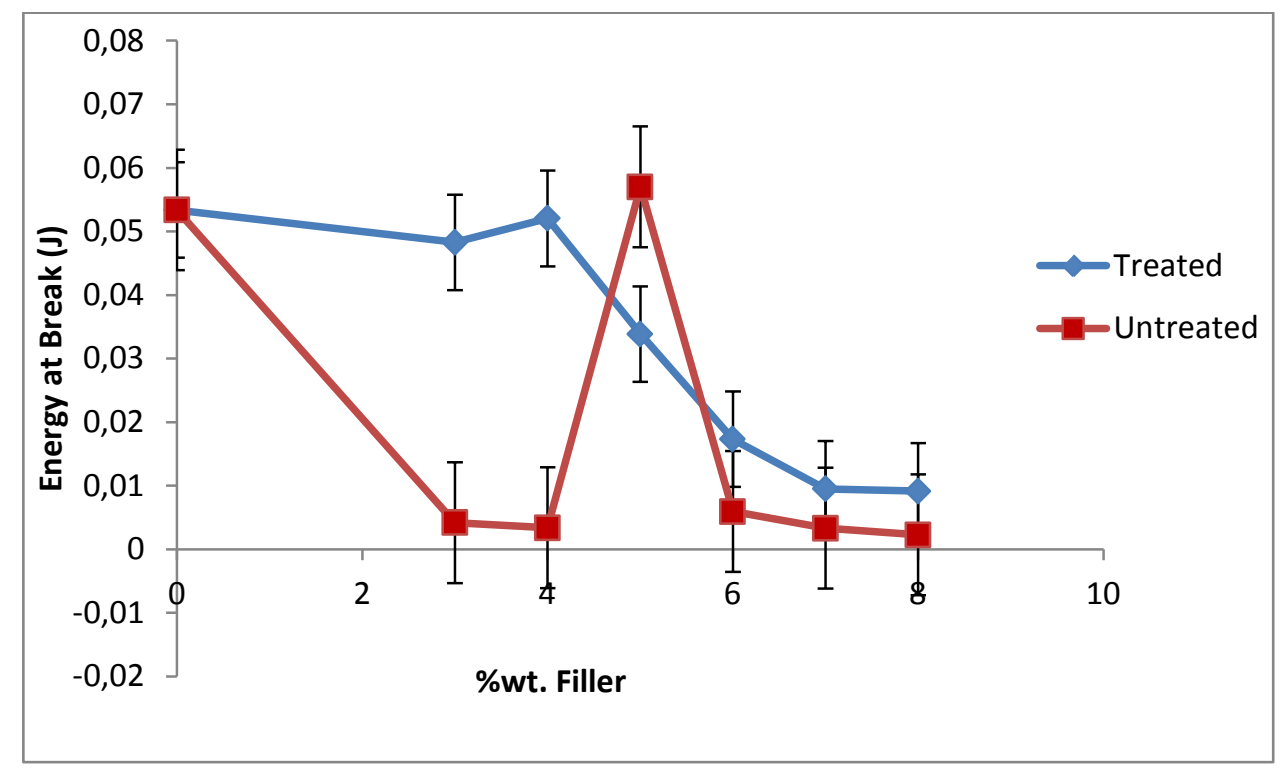

Figure 5: Energy at break of GSP-PLA nanofibre.

Figure 6 shows the Mean diameters of treated and untreated GSP-PLA nanofibres. It is evident that increase in filler addition led to increase in average fibre diameter for untreated filler composites whereas the use of treated filler particles led to initial decrease in average fibre diameter up to 5 wt. \% of filler and afterwards increase with further increase in weight fraction of filler. The untreated $3 \mathrm{wt}$ \% GSP reinforced PLA nanofibre had the smallest diameter $(\sim 7.0 \mathrm{~nm})$ while the $7 \mathrm{wt} . \%$ treated GSP reinforced PLA nanofibre 
has the highest diameter of $\sim 105 \mathrm{~nm}$. The small diameter of fibre at 5 wt. \% untreated GSP-PLA nanofibre can also be said to contribute to its high UTS and energy at break as observed in Figures 1 and 5 [15, 16]. The composite with $3 \mathrm{wt}$. \% of untreated filler is found to possess smallest diameter but low UTS in figure 1. This may be attributed to poor surface adhesion of the fillers to the polymer matrix and formation of undesirable beads on the fibre surface which is not the case in the $5 \mathrm{wt}$. \% untreated fillers as shown in figure 9c.

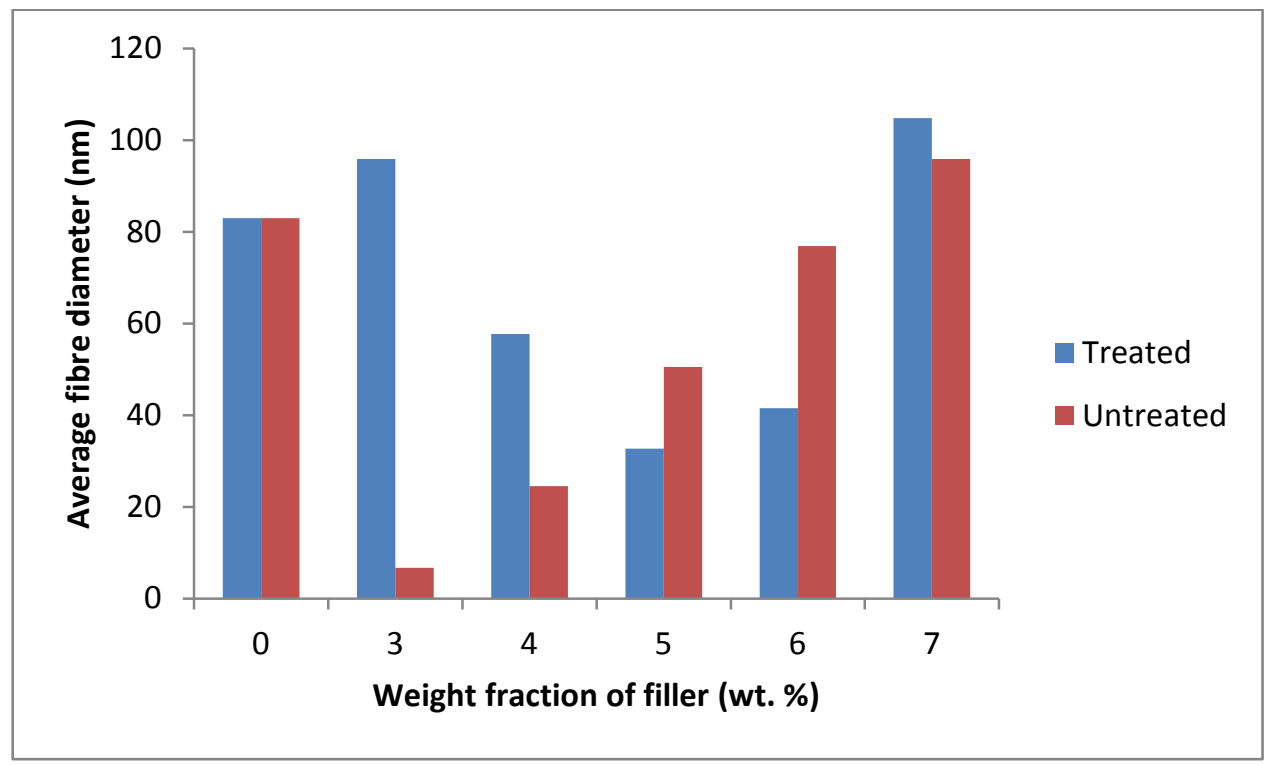

Figure 6: Mean diameter of reinforced GSP-PLA nanofibre.

\subsection{Water Absorption}

From Figure 7, it was inferred that sample with 7 wt. \% treated GSP-PLA fibre showed the best water absorption resistance. The better water resistance of the nanocomposite fibre may be attributed to the ability of thermoplastic polymers to form a protective layer at the interphase, which prevented the diffusion of water molecules into fillers. In the untreated GSP-PLA fibre, there are considerable amount of water loving constituents than in the treated GSP-PLA fibre with this phenomenon been responsible for the differences in water absorption. In a study [17] it was noted that removal of non-cellulosic substances from the fibres led to a reduction in the hydrophilic nature of the fibres making them less likely to absorb water as the water loving portion (amorphous) of the fibres was removed by the treatment.

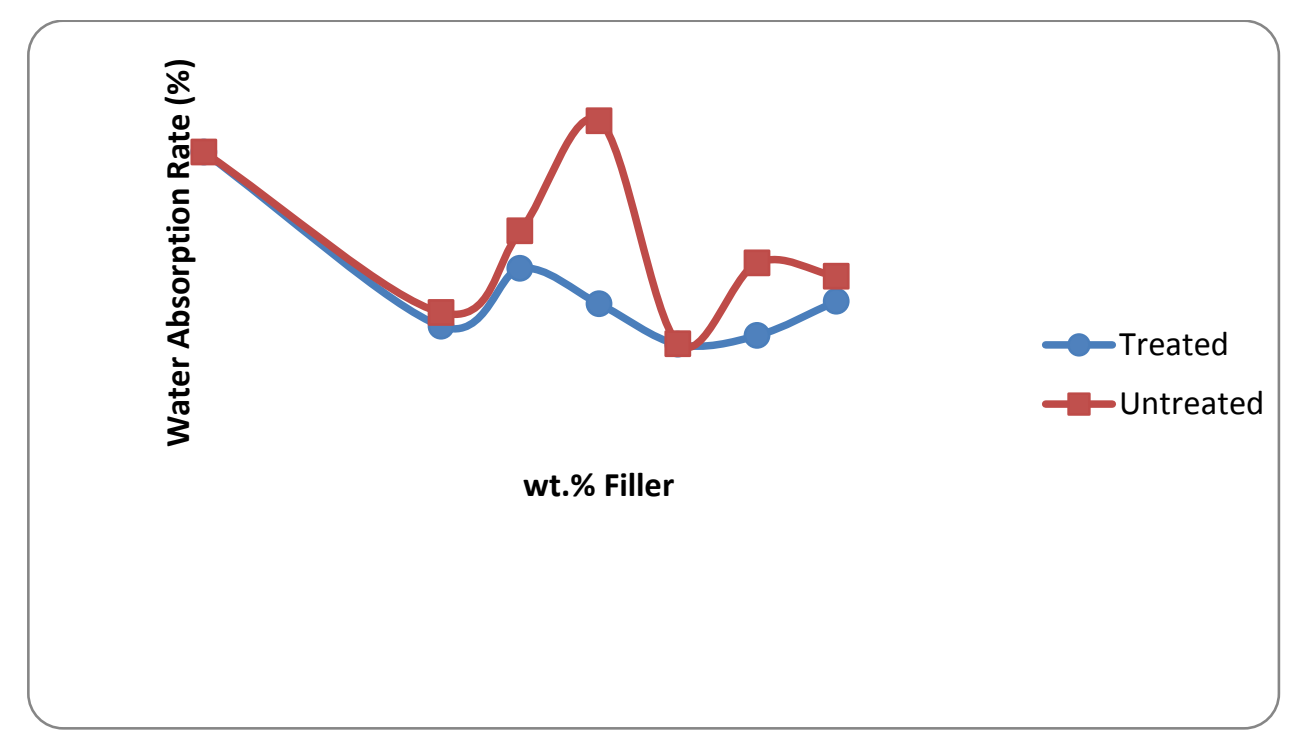

Figure 7: Water absorption rate of GSP-PLA nanofibre at $70{ }^{\circ} \mathrm{C}$. 
In Figure 8, it was observed that at $70{ }^{\circ} \mathrm{C}$, the absorption rate escalated for all the samples. Thus, at high temperatures debonding developed between the fibre and matrix creating pores for water to be absorbed. Micro cracks are also developed at the interface between the fibre and the matrix giving rise to high water absorption [18]. In addition it is believed that moisture uptake increases with increasing temperature due to increase in the velocity of water motion inside the composites. An earlier study [19] supports the idea that at elevated temperatures diffusion of penetrants into polymers follows the non-Fickian relationship.

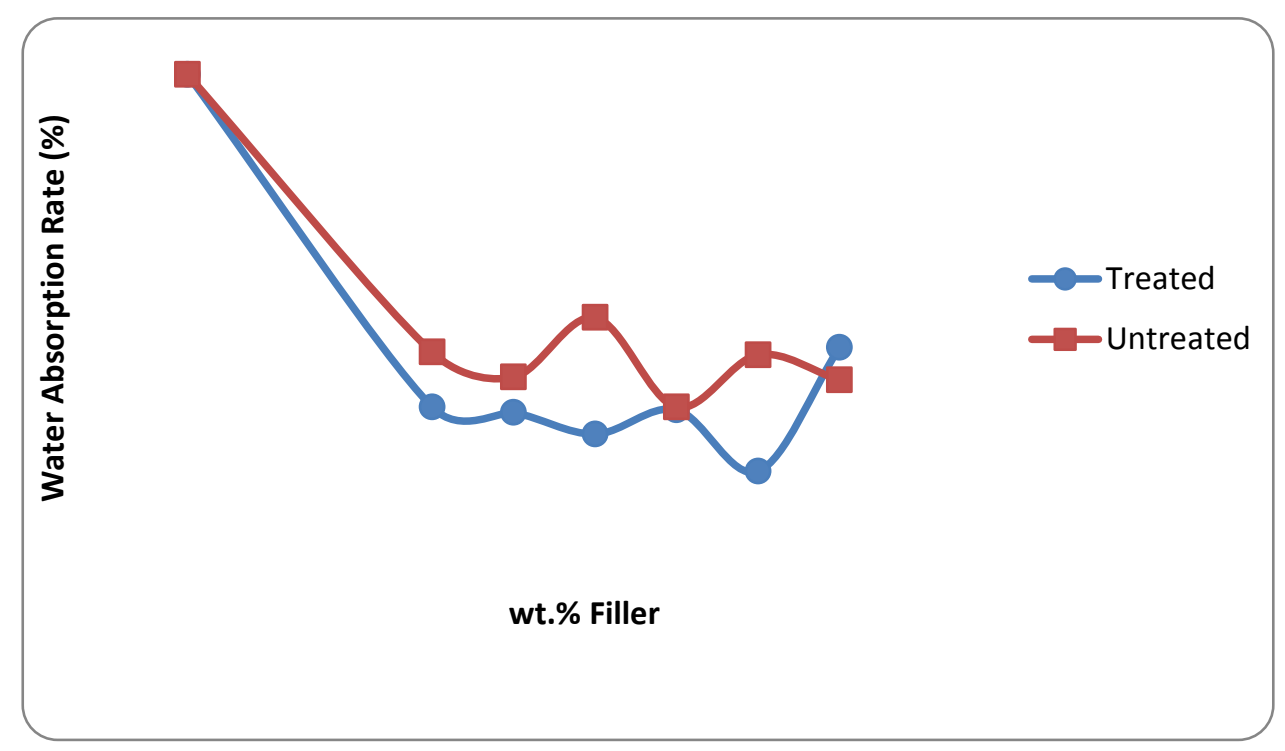

Figure 8: Water absorption rate of GSP-PLA nanofibre at ambient temperature.

\subsection{Morphologies of PLA reinforced Nanocomposite}

SEM analysis was employed to obtain qualitative evidence regarding the bond quality between the filler and matrix, and the dispersion of filler in the matrix. From the SEM micrographs, Figures 9 a-g, it was verified that less clustered fibre samples' showed higher UTS than the more clustered fibres. Figures 9a, b and c show SEM images of GSP-PLA fibre with 5 wt. \% untreated GSP, 3 wt. \% and 4 wt. \% treated respectively with no clusters having very high UTS of $0.88 \mathrm{MPa}, 0.68 \mathrm{MPa}$ and $0.41 \mathrm{MPa}$ respectively. On the other hand unreinforced nanofibre (Figure 9g), 6wt. \% untreated GSP-PLA fibre (Figure 9d), 7 wt. \% treated GSP-PLA fibre (Figure 9e), and 7wt. \% untreated GSP-PLA fibre (Figure 9f) with evidence of clustering possess lower UTS of $0.22 \mathrm{MPa}, 0.37 \mathrm{MPa}, 0.13 \mathrm{MPa}$, and $0.12 \mathrm{MPa}$ respectively. Meanwhile, beads were formed in other samples apart from unreinforced PLA fibre (Figure 9g) as shown by SEM, which is an indication of the presence and agglomeration of fillers. 


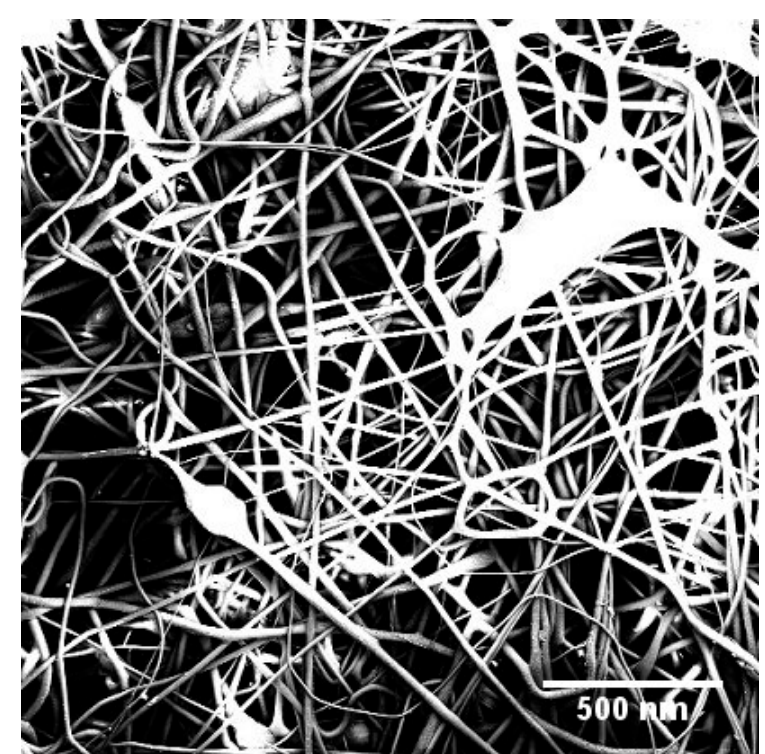

(a)

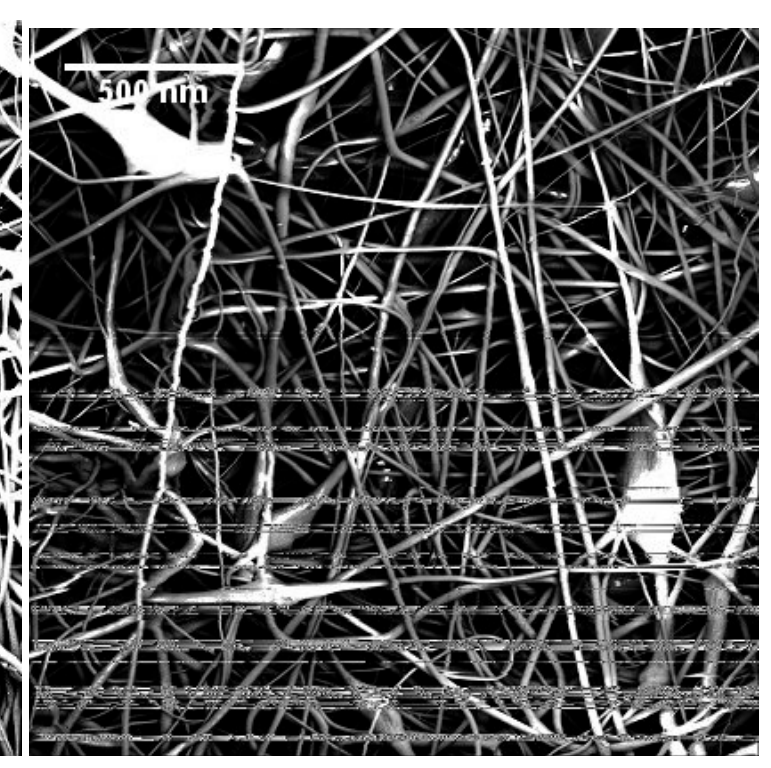

(b)

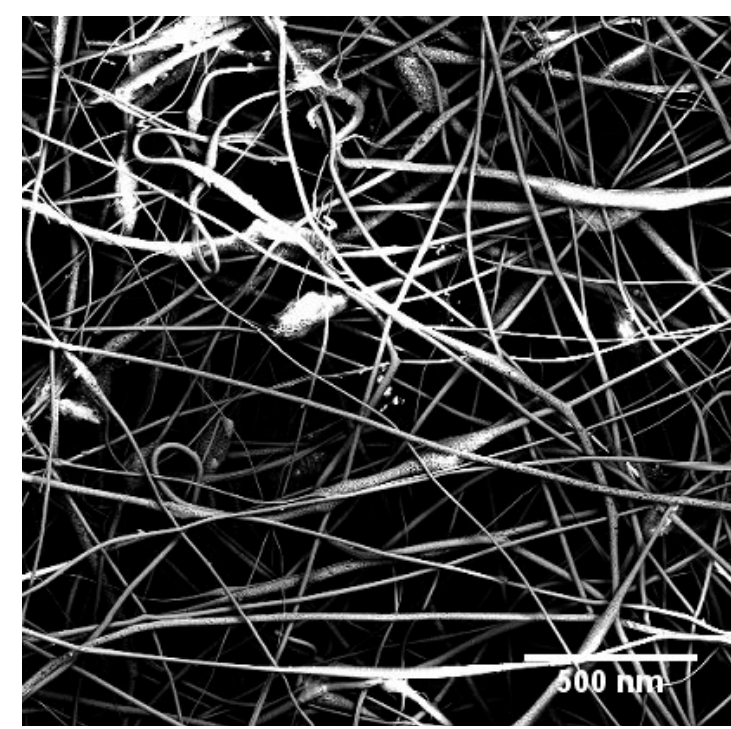

(c)

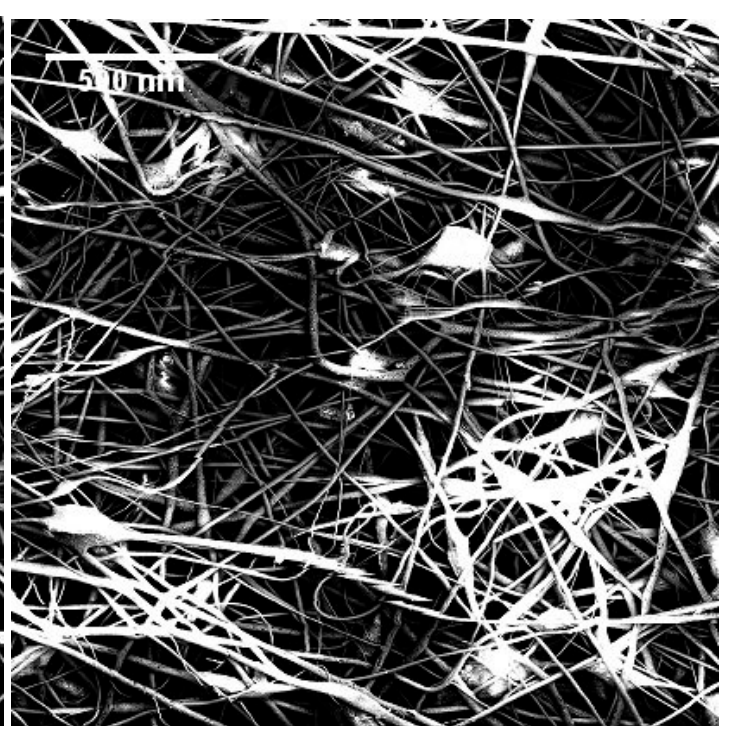

(d) 


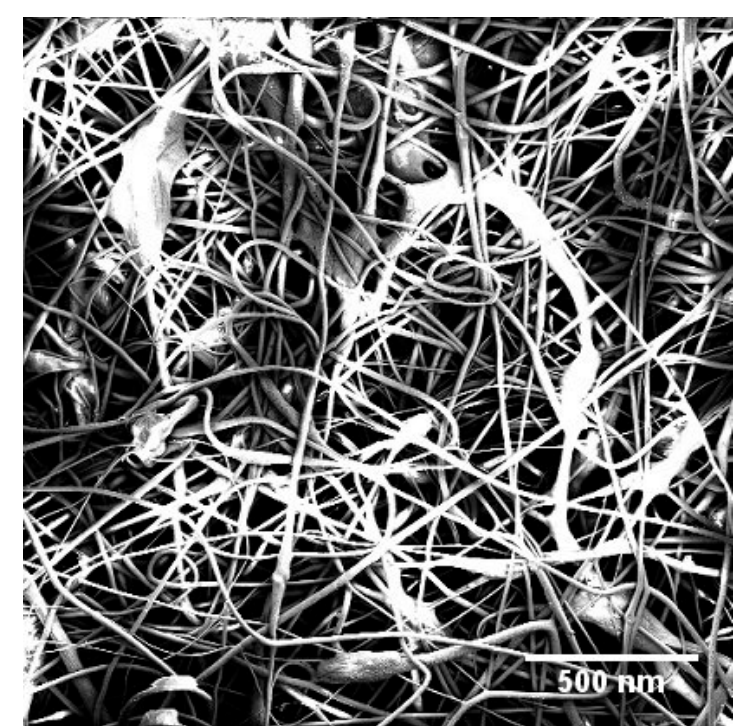

(e)

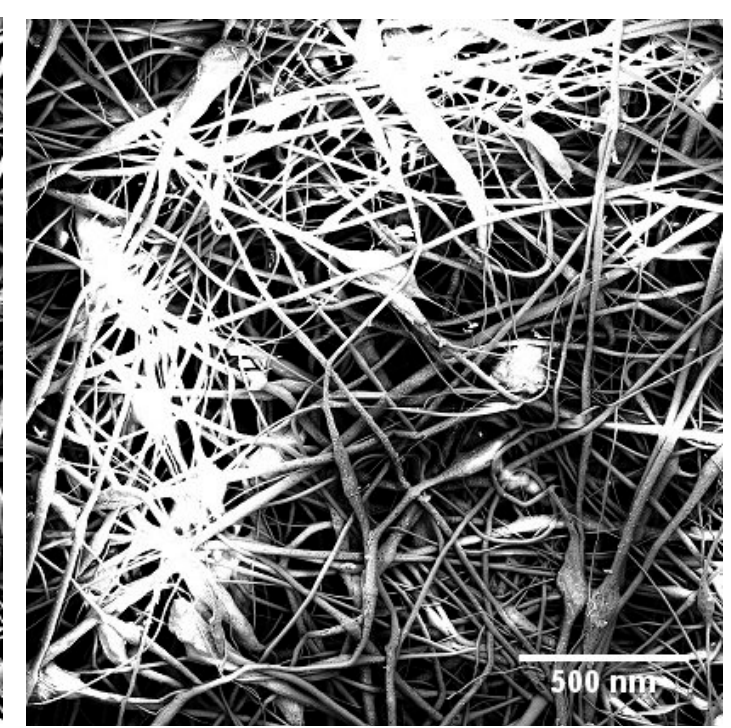

(f)

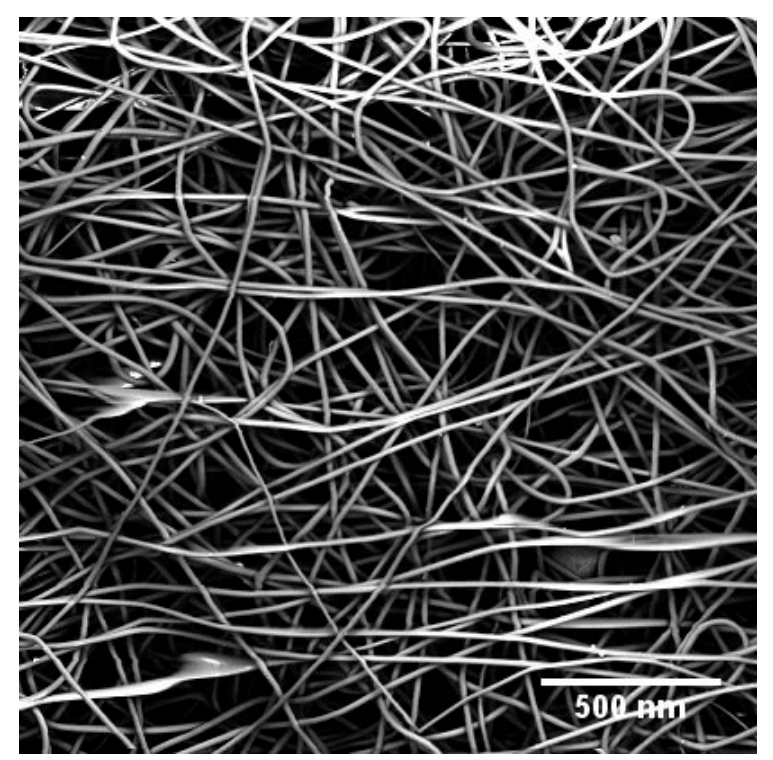

(g)

Figure 9: Morphologies of GSP-PLA nanofibre (a) 3 wt.\% treated (b) 4 wt.\% treated (c) 5 wt. \% untreated (d) 6 wt. \% untreated (e) 7 wt. \% treated (f) 7 wt.\% untreated and (g) Control sample.

\section{CONCLUSIONS}

In this work, most of the GSP-PLA nanofibres produced showed poor Modulus of Elasticity. PLA reinforced with 5 wt. \% untreated GSP indicated best blend of properties such as hardness, stiffness, UTS, energy and stress at break but fair in ductility. The nanofibre with 5 wt. \% untreated GSP had the highest UTS of 0.85 MPa. Beads were formed in reinforced fibres due to agglomeration of GSP, while the unreinforced PLA fibres have no beads. These GSP-PLA fibres produced have potential applications in packaging, tissue engineering, and drug delivery.

\section{BIBLIOGRAPHY}

[1] RAJU, G.U., KUMARAPPA, B.S, GAITONDE, C.V.N. "Mechanical and Physical characterization of agricultural waste reinforced polymer composites”, Journal of Mat. Env. Sci., v. 3, n. 5, pp. 907-916, 2012.

[2] ADEOSUN, S.O., LAWAL, G.I., BALOGUN, S.A. et al., "Review of green polymer Nanocomposites”, Journal of Minerals and Materials Characterization and Engineering, v. 11, n. 4, pp. 385-416, 2012. 
[3] KORD, B., "Investigation of Reinforcing Filler Loading on the Mechanical Properties of Wood Plastic Composites”, World App. Sci. Journal. v. 13, n. 1, pp. 171 - 174, 2011.

[4] GUMEL, S.M., ADAM, J.L., HABIBU, S., et al., "Tensile Properties of Treated and Untreated Groundnut Shell Filled Natural Rubber Composites”, Journal of Applied Chemistry, v. 7, n.10, pp. 40 - 44, 2014.

[5] ZHAOQIAN, L., XIAODONG, Z., CHONGHUA, P. "Effect of Sisal Fiber Surface Treatment on Properties of Sisal Fiber Reinforced Polylactide Composites,” International Journal of Polymer Science, v. 2011, Article ID 803428, 7 pages, 2011. doi:10.1155/2011/803428.

[6] BORBA, P.M., TEDESCO, A., LENZ, D.M., "Effect of Reinforcement Nanoparticles Addition on Mechanical Properties of SBS/Curaua Fibre Composites”, Materials Research, v. 17, n. 2, pp. 412-419, 2014.

[7] OBELE, C.M., ISHIDI, E.Y., ODERA, R.S. "Effects of Maleic Anhydride on the Mechanical Properties and Morphology of Wheat Straw Fibre Reinforced Polypropylene”, Journal of Innovative Research in Engineering and Sciences, v. 3, n. 1, pp. 412 - 420, 2012.

[8] ISHMAIL, H., EDYHAM ,M. R., WIRJOSENTONO, B. "Bamboo fiber-filled natural rubber composites: Effects of filler loading and bonding agent”, Polymer Testing, v. 21, n. 2, pp. 139-144, 2002.

[9] TSERKI, V., MATZINOS, P., KOKKOU, S., et al., "Novel biodegradable composites based on treated lignocellulosic waste flour as filler-Part I: Surface chemical modification and characterization of waste flour”, Composites Part A, v. 36, n. 7, pp. 965-974, 2005.

[10] SUPRI, A.G., LIM, B.Y. "Effects of Treated and Untreated Filler Loading on the Mechanical , Morphological and Water Absorption Properties of Water Hyacinth Fibers-Low Density Polyethylene Composites”, Journal of Physical Sci., v. 20, n. 2, pp. 85 - 96, 2009.

[11] SALMAH, H., MARLTZA, M., TEH, P.L., “Treated Coconut Shell Reinforced Unsaturated Polyester Composites”, International Journal of Engineering and Technology, v. 13, n. 2, pp. 94 - 103, 2013.

[12] FADHIL, S.M.Y, “The Production of Economical Precast Concrete Panels Reinforced by Waste Plastic Fibers”, American Journal of Civil Engineering and Architecture, v. 3, n. 3, pp. 80-85, 2015.

[13] WANG, S., ADANUR, S., JANG, B.Z. "Mechanical and thermo - mechanical filure mechanism analysis of fiber/filler reinforced phenolic matrix composites”, Composites B: Engineering, v. 28, n. 3, pp. 215231, 1997.

[14] WIETSMAN, J.Y., “Fluid Effects in Polymeric Composites”, Springer Science and Business Media, New York, 2011.

[15] INACIO, W.P, LOPES, F.P.D., MONTEIRO, S.N., "Diameter dependence of tensile strength by Weibull analysis: Part III sisal fiber”, Revista Matéria, v. 15, n. 2, pp. 124-130, 2010.

[16] PORTELA, T.G.R., COSTA, L.L., SANTOS, N.S.S., et al., "Tensile behavior of lignocellulosic fiber reinforced polymer composites: Part II buriti petiole/polyester”, Revista Matéria, v. 15, n. 2, pp. 195-201, 2010.

[17] AKPAN, E. I., ADEOSUN, S. O., LAWAL, G. I., et al., "Structural Characteristics of Batch Processed Agro-Waste Fibres”, International Journal of Chemical, Molecular, Nuclear, Materials and Metallurgical Engineering, v. 8, n. 3, pp. 230 - 237, 2014.

[18] OSMAN, E., VAKHGUELT, A., SBARSKI, I., et al., "Water absorption behavior and its effect on the mechanical properties of kenaf natural fiber unsaturated polyester composites”, In: Proceedings of the 18th international conference on composite materials, Jeju, Korea, Aug. 21 -26, 2011.

[19] DHAKAL, H.N., ZHANG, Z.Y., RICHARDSON, M.O. "Effect of water absorption on the mechanical properties of hemp fiber reinforced unsaturated polyester composites”, Composites Science and Technology, v. 67, n. 7-8, pp. 1674-1683, 2007. 